\section{Commentary: Minimally invasive thoracic surgery must provide proper oncologic margin-How to facilitate it?}

\author{
Tomasz Grodzki, MD, and Jarosław Pieróg, MD
}

Optimal lung tumor postsurgical free margin has been a crucial subject of vivid debate and investigation. Incomplete resection with positive margins is known as worsening prognostic factor regarding long-term lung cancer survival irrespective of stage. ${ }^{1}$ It is believed the margin status may by improved by the use of an electromagnetic navigation bronchoscopy (ENB) procedure, which provides more accurate dye marking visualization of a nodule surrounded by lung parenchyma during video-assisted thoracoscopic surgery. ${ }^{2,3}$ ENB has been used for the accurate placement of fiducial markers to facilitate stereotactic radiation therapy treatment in selected patients with lung cancer. ${ }^{4}$ Novel ENB applications include placement of ablation probes in a target tumor and guidance of endobronchial ablation catheters for the minimally invasive treatment of lung cancer. ${ }^{5}$

The authors presented a new application of ENB by using fiducial markers to help resect a lung nodule radically. The report prompts problems in identifying nodules or groundglass opacity to obtain adequate margins. ENB has been demonstrated as a tool for triple-contrast dye marking to provide accurate nodule localization and for implantation of fiducial markers to perform a stapler line with adequate margin in the hybrid operation theater. The approach seems to be an appropriate way to resect "the difficult to visualize" nodule radically. However, migration or difficulty in implantation of the fiducial marker in the vicinity of the tumor can be a problematic issue. The novel approach proposed by

From the Department of Thoracic Surgery and Transplantation, Pomeranian Medical University, Szczecin, Poland.

Disclosures: The authors reported no conflicts of interest.

The Journal policy requires editors and reviewers to disclose conflicts of interest and to decline handling or reviewing manuscripts for which they may have a conflict of interest. The editors and reviewers of this article have no conflicts of interest.

Received for publication July 23, 2020; revisions received July 23, 2020; accepted for publication July 31, 2020; available ahead of print Aug 11, 2020.

Address for reprints: Tomasz Grodzki, MD, Department of Thoracic Surgery and Transplantation, Pomeranian Medical University, Sokołowskiego 11, 70-891 Szczecin, Poland (E-mail: grodzki@grodzki.szczecin.pl).

JTCVS Techniques 2020;3:334-5

2666-2507

Copyright (c) 2020 The Authors. Published by Elsevier Inc. on behalf of The American Association for Thoracic Surgery. This is an open access article under the CC BY-NCND license (http://creativecommons.org/licenses/by-nc-nd/4.0/).

https://doi.org/10.1016/j.xjtc.2020.07.031

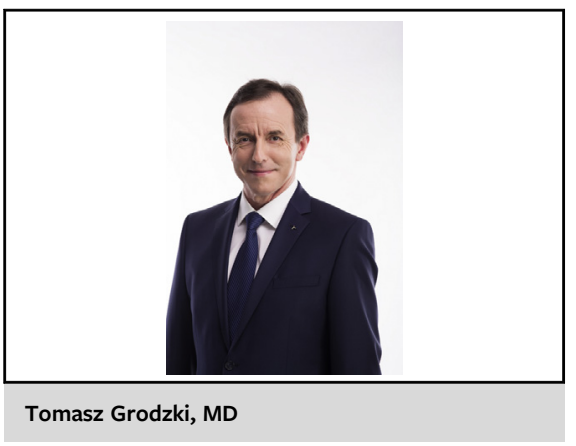

CENTRAL MESSAGE

Fiducial marker placement and triple-contrast dye marking of lung lesions during electromagnetic navigation bronchoscopy provides accurate localization and ensures adequate resection margin.

the authors is interesting, and it would be a valuable option for the pulmonary nodules surrounded by the lung parenchyma. Needless to say, ENB along with cone-beam computed tomography is a sophisticated, time-consuming procedure that requires well-trained medical staff. It limits this kind of the approach to the well-experienced centers; therefore, it would not be widely performed. ENB facilitates bronchoscopic sampling of peripheral pulmonary nodules. Nodule sampling may be performed with a variety of instruments, including forceps, cytology brushes, transbronchial needles, or cryoprobe. It should be noted this method provides samples that can be evaluated during the ROSE procedure (rapid on-site evaluation). Bronchoscopic transparenchymal nodule access and the transbronchial access tool are novel techniques that leverage navigational bronchoscopic technologies to further improve access to lesions throughout the lung. The devices used for sampling tissue have similarly evolved, such as the introduction of cryobiopsy. The tools allow one to take samples of the desired resection margin before the fiducial marker implantation. The frozen section of the taken samples would confirm the adequate margin to make sure the pulmonary nodule is resected radically. Localization of peripheral pulmonary lesion guided by electromagnetic navigation and minimally invasive resection proved that this technique has been an accurate and safe alternative for visualization and adequate resection of the small pulmonary nodules. 
Thoracic surgeons should further investigate this method while trying to apply it to clinical practice.

\section{References}

1. Osarogiagbon RU, Lin CC, Smeltzer MP, Jemal A. Prevalence, prognostic implications and survival modulators of incompletely resected non-small-cell lung cancer in the US national cancer data base. J Thorac Oncol. 2016;11:5-16.

2. Krimsky WS, Minnich DJ, Cattaneo SM, Sarkar SA, Harley DP, Finley DJ, et al. Thoracoscopic detection of occult indeterminate pulmonary nodules using bronchoscopic pleural dye marking. J Community Hosp Intern Med Perspect. 2014;4:23084.
3. Chan JWY, Lau RWH, Ng CSH. Electromagnetic navigation bronchoscopy fiducial marker margin identification plus triple dye for complete lung nodule resection. J Thorac Cardiovasc Surg Tech. 2020;3:329-33.

4. Anantham D, Feller-Kopman D, Shanmugham LN, Berman SM, DeCamp MM, Gangadharan SP, et al. Electromagnetic navigation bronchoscopy-guided fiducial placement for robotic stereotactic radiosurgery of lung tumors: a feasibility study. Chest. 2007;132:930-5.

5. Narsule CK, Sales Dos Santos R, Gupta A, Ebright MI, Rivas R Jr, Daly BDT, et al The efficacy of electromagnetic navigation to assist with computed tomographyguided percutaneous thermal ablation of lung tumors. Innovations (Phila). 2012;7: 187-90. 